\title{
PERANCANGAN BRAND IDENTITY VCO BUNDO KANDUANG
}

\author{
Stefvany ${ }^{1}$, Yosa Fiandra ${ }^{2}$ \\ Program Studi Desain Komunikasi Visual, Institut Seni Indonesia Padang Panjang ${ }^{1}$ \\ Program Studi Desain Komunikasi Visual, Telkom University ${ }^{2}$ \\ stefvanyy@gmail.com ${ }^{1}$ \\ pichaq@telkomuniversity.ac.id ${ }^{2}$
}

\begin{abstract}
Abstrak
Perancangan ini memiliki tujuan untuk merancang sebuah Brand identity yang sesuai dengan ciri khas, efektif, dan berbeda dengan kompetitor lain. Manfaat dari perancangan ini agar terciptanya Brand Identity VCO Bundo Kanduang sehingga lebih dikenal oleh masyarakat dan konsumen. Hasil analisa dan ilmu pengetahuan ini dapat dijadikan dokumen dan acuan referensi bagi perancang selanjutnya dalam berkarya. Metode penelitian dilakukan dengan menggunakan studi literatur dan penelitian dengan pendekatan kualitatif dengan tahap, observasi, wawancara dan dokumentasi. Metode perancangan dalam penelitian ini menggunakan pendekatan metode brainstorming. Diharapkan logo dan Brand Identity dapat menyasar kepada target audience secara tepat karena ditempatkan pada media-media yang cukup sering ditemui oleh target, dan perancangan tersebut nantinya bisa digunakan oleh perusahaan VCO Bundo Kanduang seperti penunjang mutu dan kualitas produk mereka dalam mempromosikan produk kepada konsumen.

Kata Kunci: Perancangan, Identity Branding, VCO Bundo Kanduang

Abstract

This design aims to design an Identity Branding with specific charaacteristics, effective and different from other competitors. The benefit of this design is to create the Brand Identity of the Bundo Kanduang VCO hence it is better known by the public and consumers. The results of this analysis and knowledge can be used as documents and references for the future designers. This research was literature study and a qualitative approach with three stages; observations, interviews, and documentation. The design method in this study was the brainstorming method approach. Furthermore, it is hoped that the logo and Brand Identity can get the right target audience because they are placed on media that are quite often encountered by the target, and the design can later be used by the Bundo Kanduang VCO Company as supporting the quality of their products in promoting products to costumers.
\end{abstract}

Keyword: Design, Identity Branding, Bundo Kanduaang VCO

\section{PENDAHULUAN}

Padang Pariaman aadalah salaaah satu Kabupaten penghasil kelapa terbanyak di Sumatera Barat. Kecamatan Sungai Geringging adalah penghasil kelapa terbanyak dan mempunyai kuaalitas buah yang di Padang Pariaman. Tahun 2011 diadakan pelatihan kewirausahaan oleh kelompok tani Sukaa Fajarm untuk masyarakat di Desa Mengaum, setelah beberapa kali pelatihan, termotivasi untuk mengolah kelaapa menjadi VCO, oleh seorang rumah tangga bernama Inut Marlini yang mempunyai kebun kelapa yang cukup luas didesa tersebut. usaaha ini dirilis pada pertengahan tahun 2011, dan di beri nama VCO Bundo Kanduang.

VCO memiliki banyak keunggulan, selain mengobati kanker juga untuk penyakit dalam lainnya. Manfaaat VCO umumnyaa mendapatkan cap buruk karena mengaaandung lemak jenuh yang tingi. Naamun, sebenarnya terdapat berbagai manfaat dari minyak kelapa, khususnya jenis minyak kelapa yang disebut sebagai Virgin Coconut Oil (VCO).

Ketiadaan identitas visual produk sebagai penanda ciri khas dan pembangun brand juaga menjadi salah satu permasalahan yang timbul. VCO Bundo Kanduang terbilaang masih sederhana, selain itu tampilan kemasan produk ini pun masih menggunakaan botol plastik biasa dan label penanda yang seadanya, tidaak memiliki kemasan yang menarik yang dapat menunjang identitas brand usaha itu sendiri, dapat dikatakan belum mempunyai ciri khas tersendiri dari produk pesaing yang ada disekitarnya. VCO Bundo Kanduang juga belum mempunyai logo nya sendiri.

Melihat permasalahan yang ada dan berdasarkan observasi dan wawancara dengan pemilik VCO Bundo Kanduang, perancangan Brand Identity VCO Bundo Kanduang adalah jawaban permasalahan tersebut. perancangan brand identity ditujukan agar masalah ini dapat teratasi dengan cara membuat identitas VCO Bundo Kanduang sehingga dapat menciptakan brand identity yang dapat menjadi pengenal yaaang benar-benaar mewakili karakter dari VCO Bundo Kanduang dan menjadi sebuah penanda yang dikenali oleh konsumen saat membeli produk VCO Bundo Kanduang.

Dengan adanya Braand Identity ini diharapkaan akan sangat membantu VCO Bundo Kanduang dalam hal publikasi citra usahanya. Karena dalam brand identity yang dibuat ini mencerminkan karaakteristik perusahaan dan juga didukung dengan berbagai merchandise yang berhubungan dengan konsep yang ingin diangkat oleh VCO Bundo Kanduang. 


\section{TINJAUAN PUSTAKA}

\section{Branding}

a. Identifikasi Branding

Branding merupakan nama barang atau jasa yang membedakan dengan milik pesaing [1]. Brand adalah merek yang memiliki reputasi yang menjanjikan, sehingga publik mempercayai dan memilih merek tersebut. Brand merupakan identitas produk/jasa yang yang ditawarkan [1].

\section{b. Manfaat dan Peran Branding}

Manfaat brand adalah mampu memebuhi perkembangan tuntutan kebutuhan konsumen. Karna pada masa sekarang konsumen tidak lagi membeli produk untuk memenuhi keperluan yg bersifat fungsi, fisikal dan rasional; konsumen masa kini membeli untuk memenuhi keinginan yg diwarnai unsur non-fungsional, psikis, aspirasional dan emosional [1]. Ada beberapa manfaat pokok Branding bagi konsumen, yaitu sebagai : identifikasi sumber produk, penetapan tanggung jawab pada manufakatur atau distributor tertentu, signal kualitas, alat untuk memproyeksi Citra diri, ikatan khusus dengan produsen, penekanan biaya pencairan internal, dan pengurang resik.

\section{c. Unsur-Unsur Branding}

Unsur terpentimg dalam sebuah bramd adalah nama/ merek suatu produk. Brand tidak cukup hanya didukung dengan lambamg atau simbol identitas visual tetapi harus secara konsisten dan sistematis diterapkam pada berbagai media komunikasi pemasaran suatu brand.

\section{d. Strategi Brand}

Dalam membangun brand suatu produk/ jasa, harus memiliki tiga langkah utama yaitu membentuk persepsi, membangun kepercayaan,dan membangun cinta (kepada brand) [1].

Strategi branding digunakam untuk mengenalkan nilai-nilai bisnis kepada konsumen. Strategi branding harus menyampaikan kekhasan seperti nama, logo, merk, tagline, slogan hingga penggunaan warna khusus untuk mengenali brand tersebut ke target pasarnya [7].

e. Identitas Visual

Identitas adalah gambaran produk suatu perusahaan, identitas digunakan untuk membedakan produk satu dengan yang lainnya. Identitas yang ditambilkan secara konsisten akan memberikan gambaran kepada masyarakat sehingga dapag meningkatkan brand awareness dan brand image yang positif di benak masyarakat.

\section{f. Jenis-Jenis Branding}

a. Product Branding; Bertujuan untuk mendorong konsumen agar lebih memilih produk yang dibranding ketimbaang produk pesaing.

b. Personal Branding; Alat pemasaran yang digunakan untuk mengangat nama seorang public figur, missal politisi, selebriti, dll. dengan begitu public figur tersebut mendapat citra yang baik di masyarakat.

c. Corporate Branding; Untuk meningkatkan reputasi sebuah perusaahaan di pasar, meliputi semua aspek tersebut mulai dari produk/jasa yang ditaawarkan hingga kontribusi karyawan terhadap masyarakat.

d. Geographic Branding; Bertujuan untuk memunculkan gambaran dari sebuah produk/jada ketika nama lokasi tersebut disebutkan seseorang

e. Cultural Branding; Bertujuan untuk mengembangkan reputasi mengenai lingkungan dan orang-orang dari lokasi tertentu.

\section{Virgin Coconut Oil (VCO)}

Virgin Coconut Oil (VCO), merupakan minyak kelapa murni yang diolah secara alami tanpa adanya pengawet sedikipun, di olah dari buah kelapa segar yang di petik langsung dari kebun nya. Pengolahan VCO membutuhkan waktu yang cukup lama, karena menggunakan cara yang sangat alami, supaya bisa mempertahkan kualitas serta kandungan yang terdapat pada VCO itu sendiri.

Proses pengolahan VCO yang membutuhkan waktu cukup lama karena melalui banyak tahapan sebelum bisa di konsumsi dan di gunakan oleh konsumen, mulai dari pemilihan buah kelapa yang sudah tua, pemarutan, pemerasan (pemisah santan dengan ampas), pengendapan (pemisah air dengan minyaak), setelah semua proses di lalui barulah VCO bisa dikonsumsi dan digunakan oleh konsumen. 


\section{VCO Bundo Kanduang}

Di Kecamatan Sungai Geringging banyak terdapat perkebunan kelapa yang mempunyai kualitas buah yang baik. Pada tahun 2011 diadakan pelatihan kewirausahaan oleh kelumpuk tani Suka Fajar, untuk masyarakat di Desa Batu Mengaum, setelah beberapa kali pelatihan dan pertemuan, timbulan ide untuk mengolah Kelapa menjadi VCO, oleh seorang ibu rumah tangga yang bernama Inut Marlini, yang beralamat di Amacang Gata, Batu Mengaum, Sungai Geringging, Kabupaten Padang Pariaman yang mempunyai kebun kelapa yang cukup luas di desa tersebut. Usaha ini dirilis pada pertengahan tahun 2011, dana diberi nama VCO Bundo Kanduang, dimana VCO ini banyak keunggulan, selain dapat mengobati kanker bisa juga untuk penyakit lainnya.

\section{PERANCANGAN}

\section{Konsep Perancangan}

a. Konsep Verbal

Konsep verbal yang diutamakan dari VCO Bundo Kanduang yang maknanya akan menimbulkaan citra bahwa VCO Bundo Kanduang merupakan minyak kelama yang murni yang aman untuk dikonsumsi dengan harga yang terjangkau. Untuk mencapai suatu tujuan yaitu kepuasaan pelanggan, kepercayaan pelanggan terhadap produk dan kemajuan VCO Bundo Kanduang

b. Konsep Visual

Visual yang menggambarkan dari karakter VCO Bundo Kanduang antara lain meliputi ilustrasi yang diaptasi dari bentuk Kelapa dan Bundo Kanduang. menggunakan tipografi, warnaa yang digunakan yaitu warna-warna khas Minangkabau yaitu merah, kuning, hijau. Kriteria dari logo yang akan dirancang yaitu unik, simple dan modern, diolah sedemikian rupa, hingga membentuk sebuah logo yang diinginkan.

\section{Pra Desain}

a. Jenis Karakteristik Logo

Dalam merancangan logo VCO Bundo Kanduang yang digunakan yaitu logo kombinasi, logo kombinasi adalah logo yang terdiri dari gabungan tulisan/huruf dan gambar, logo abstrak, atau mascot. gambar dan teks dapat diletakkan berdampingan, ditumpuk satu sama lain, atau diintegrasikan Bersama untuk membuat gambar.

b. Alternatif Sketsa

Proses pencarian ide dimulai dengaan melakukaan beberapa alternatif sketsa, dimulai dari pencarian bentuk, makna, visual yang mengarah ke konsep, berikut adalah tahapan yang dilakukan dalam perancangan.

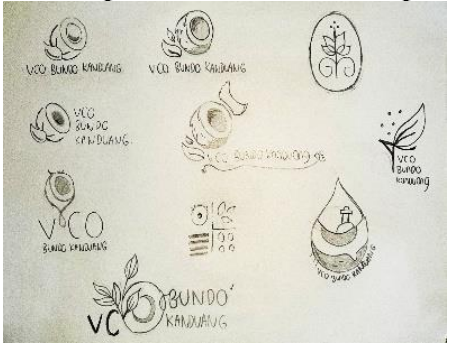

Gambar 1 Sketsa

Sumber : Dokumen pribadi

Setelah proses penggarapan sketsa dilakukan, tahapan selanjutnyaa adalaah memilih beberapa pilihan yang terbaik, dan dikembangkan lagi menjadi beberapa bentuk awal dari pilihan tersebut, dan didapatlan desain sebagai berikut :

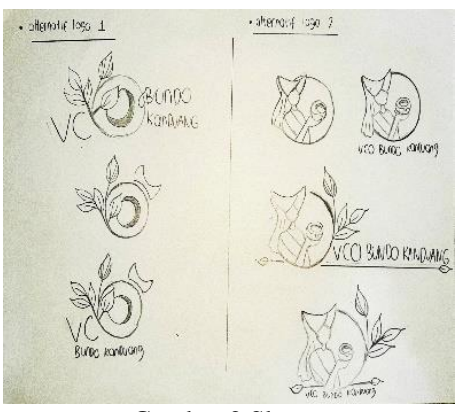

Gambar 2 Sketsa

Sumber : Dokumen pribadi 


\section{c. Final Logo}

Setelah melakukan beberapa tahapan proses perancangan logo, dan melakukan penyederhanaan setelah konsultasi dengan pemilik usaha, maka telah mendapatkan logo terbaaik, dilihat dari bentuk, tipografi, warna dan makna. logo yang mewakili suatu arti perusahaan daan. sesuai dengan visi misi usaha VCO Bundo Kanduang

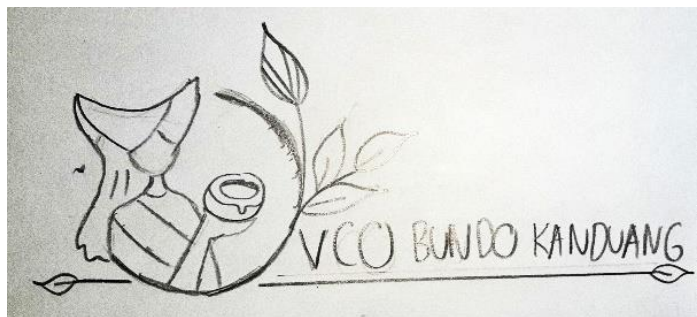

Gambar 3 Sketsa Final

Sumber : Dokumen pribadi

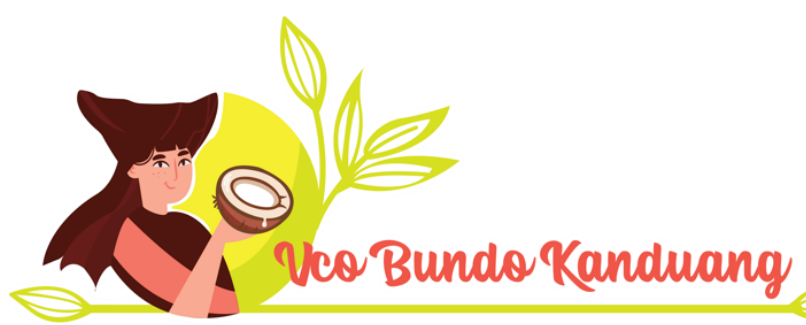

Gambar 4 Digital Final Logo

Sumber : Dokumen pribadi

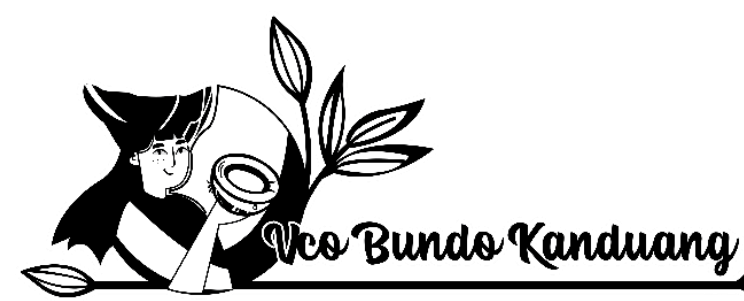

Gambar 5 Fnal Logo Black and White

Sumber : Dokumen pribadi

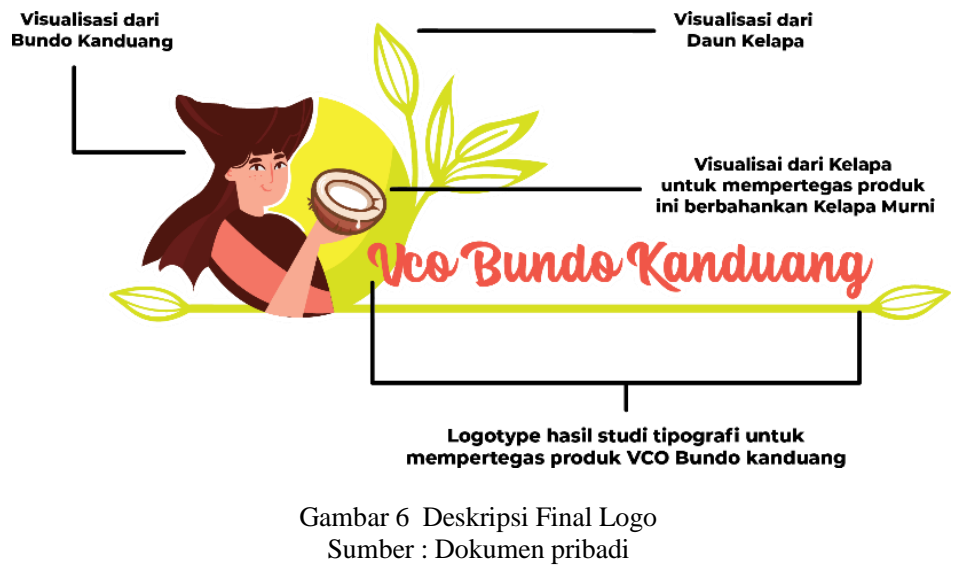


IV. KESIMPULAN

Perancangan Brand Identity VCO Bundo Kanduang bertujuan untuk membangun citra yang lebih baik daari sebelumnya melalui media komunikasi visual kepada khalayak umum. Melalui perancangan ini diharapkan semakin banyak masyarakat mengenal VCO Bundo Kanduang daan cakupan produksi pun bisa meluas dari pada sebelumnya, dapaat bersaing lebih mudah daan unggul.

Secara umum, perancangan brand identity sebagai identitas perusahaan sekaligus memprompsikan perusahaan kepada masyarakat untuk mendapatkan citra yang lebih baik lagi agar menambah minat masyarakat luas. Selain itu, brand adalah identitas untuk membedakan satu denga yang lain dan tanda kepemilikan untuk membedaakan milik usaha walaupun bergerak di bidang yang sama. Kemudian aplikasi perancangan sebagai aalat memvisualkan citraa kepada khalayak umum bahwa perusahaan tersebut konsekuen dan professional sekaligus untuk mencegah pembajakan dari sebuaah image perusahaan.

\section{REFERENSI}

[1] Neumeie, Marty. 2006. "The Brand Gap", Barkeley : New Riders.

[2] Rustan, Surianto. 2008. Mengenal Logo, Jakarta : Gramedia Pustaka Umum

[3] Rustan,Surianto. 2009. Layout Dasar dan Penerapannya. Jakarta : Gramedia Pustaka Utama.

[4] Sugono, Dendy, dkk. 2008. Kamus Besar Bahasa Indonesia. Jakarta : Gramedia Pustaka Utama

[5] Mayang, Riska. 2019. Perancangan Branding Karupuak Jangek Pusako Minang" Skripsi. Padang : DKV UPI "YPTK"

[6] (2021) Contoh Strategi Branding Yang Baik. [Online]. Available : http://www.dreambox.id/blog/contoh-strategi-branding-yang-baik/ 